Int. J. Electrochem. Sci., 13 (2018) $4901-4910$

International Journal of

ELECTROCHEMICAL

SCIENCE

www.electrochemsci.org

\title{
Fabrication of Poly (Toluidine Blue O) Functionalized Multiwalled Carbon Nanotubes on Glassy Carbon Electrode for Hydrazine Detection
}

\author{
Balasubramanian Sriram ${ }^{1}$, Tse-Wei Chen ${ }^{2}$, Shen-Ming Chen ${ }^{2, *}$, Karuppasamy Kohila rani ${ }^{1}$, \\ Rajkumar Devasenathipathy', Sea-Fue Wang ${ }^{1, *}$ \\ ${ }^{1}$ Department of Materials and Mineral Resources Engineering, National Taipei University of \\ Technology, Taipei, Taiwan. \\ ${ }^{2}$ Electroanalysis and Bioelectrochemistry Lab, Department of Chemical Engineering and \\ Biotechnology, National Taipei University of Technology, No. 1, Section 3, Chung-Hsiao East Road, \\ Taipei 106, Taiwan, ROC. \\ *E-mail: smchen78@ms15.hinet.net, sfwang@ntut.edu.tw
}

doi: $10.20964 / 2018.05 .65$

Received: 25 January 2018 / Accepted: 13 March 2018 / Published: 10 April 2018

Herein, we present an amperometric sensor for hydrazine developed via simple potentiodynamic electrochemical polymerization of O-Toluidine Blue (pTBO) on functionalized multi walled carbon nanotubes $(f-$ MWCNTs) coated glassy carbon electrode (GCE). The obtained of $f$-MWCNTs/pTBO composite was confirmed through FESEM, EDX and cyclic voltammetric studies. Relative to pTBO modified electrodes, $f$-MWCNTs/pTBO modified GCE displayed a well-defined electro-oxidation peak current response towards the detection of hydrazine. $f$-MWCNTs/pTBO/GCE exposes its good electrocatalytic ability in a wide linear range from $1 \mu \mathrm{M}$ to $357 \mu \mathrm{M}$. Our modified electrode also possesses low limits of detection $(0.24 \mu \mathrm{M})$ with high sensitivity $\left(2492 \mu \mathrm{A} \mathrm{mM} \mathrm{mm}^{-1}\right)$ value. The successful demonstration of feasible practicality of $f$-MWCNTs/pTBO composite modified GCE was performed in untreated rain, lake and tap water samples.

Keywords: Amperometric sensor, O-Toluidine Blue, Functionalized multi walled carbon nanotubes, Hydrazine.

\section{$\underline{\text { FULL TEXT }}$}

(C) 2018 The Authors. Published by ESG (www.electrochemsci.org). This article is an open access article distributed under the terms and conditions of the Creative Commons Attribution license (http://creativecommons.org/licenses/by/4.0/). 